\title{
Application of Heuristic Teaching in Higher Vocational Education Teaching of Track and Field Course Sprint
}

\author{
Wei Huang \\ School of Tourism Commerce Vocational of Jiangx University , Nanchang 330100, China. \\ 905750263@qq.com
}

Keywords: Heuristic teaching; vocational colleges; Public Course of Track and Field; dash; Application.

\begin{abstract}
Heuristic teaching is primarily a sport played by teachers under the leading role in the students' desire for knowledge, proactivity, creativity fully mobilized as quickly as possible to enable students to acquire knowledge and technical essentials of each lesson learned inductive teaching methods. In this paper, experiments and mathematical statistics, the use of PE teachers of language charm, the release signal, recorded video, and other ways of teaching the game, content to study the Heuristic Teaching on Higher Colleges of Higher Vocational Education Course Sprint Track and Field Teaching influences. Study: heuristic teaching for Higher Vocational Education Teaching sprint track and field course affect the results than the traditional method of teaching is more significant, it can increase without Sprint-based student enthusiasm, initiative and curiosity.
\end{abstract}

\section{PREFACE}

Given the current higher vocational colleges themselves increasingly clear mission, the goal of higher vocational education colleges also will be determined, but in the current environment in the education reform process in Physical Education Reform in Higher Vocational College is still relatively slow, which "Track and Field "sports is currently in Teachinsg has tended backwards, specific performance: track and field teachers teaching methods and more traditional single student learning motivation is poor, schools and other relatively low degree of attention. "Track and Field" Sport has always been scholars, activist known as "the mother of movement," which covers the "walk", "run," "jump", "vote for" a number of basic human qualities; it sports its learning direct assistance action, and the "Track and Field" learning to some extent, indeed weaker than the "basketball", "aerobics", "football" and other projects full of fun, competition, fierce resistance, but in the current educational philosophy, teaching ideas, teaching theoretical innovation, how to enable students to recognize the importance of "Track and Field" project; how to combine a new era of educational technology, teaching methods, teaching organizations is particularly important! From the heuristic teaching method for learning Sprint demonstrate this perspective, new teaching methods to find out the current track and field teaching impact, so as to provide reference for the corresponding theory of Track and Field Teaching.

\section{RESEARCH OBJECT AND METHODS}

\subsection{Research obiect}

Jiangxi Vocational College of tourism business from randomly selected freshman, four classes twenty-two year total 320 students as subjects. In order to make the results more objective truth, this experiment double-blind experimental design, random sampling approach would mean that the experimental subjects were divided into two groups, the control group, the experimental group. 


\subsection{Research Methods}

\subsection{1 literature}

Travel through Jiangxi Vocational College of Commerce in China HowNet Library, Chinese Journal Full-text Database, Wanfang database and other databases with a large collection of heuristic teaching method sprint relevant journal articles; also lending a dash of teaching methods, heuristic teaching, etc. theory books that lay a solid foundation for this study.

\subsection{2 teaching experiment}

This paper uses comparison between groups, the experimental method in the group, first for all aspects of the sprint technique teaching - the experimental and control groups were using traditional teaching, heuristic teaching, then the experimental results to analyze the differences between the two groups before and after the experiment .

\subsection{3 mathematical statistics}

Pretreatment 1) Data: Before test experiment, two groups of students after the test quality indicators related to Sprint, and then enter the relevant indicators EXCEL2007 software summary.

2) Independent-Samples $T$ test: the former experiment were entered after the test quality metrics related to test summary SPSS19.0 for Windows software T test, its purpose is to identify the experimental group and control group differences, thus effectively targeted analysis.

\section{RESULTS AND ANALYSIS}

\subsection{Comparative analysis of the experiment before the experiment group and the control group related test data}

table 3-1 Statistics experimental group and the control group before the experiment related quality index test and $\mathrm{T}$ test

\begin{tabular}{cccc}
\hline & number of people & 100 meters & 200 meters \\
\hline experimental group & 160 & $14.56 \mathrm{~s}$ & $25.36 \mathrm{~s}$ \\
control group & 160 & $14.65 \mathrm{~s}$ & $26.12 \mathrm{~s}$ \\
$\mathrm{P}$ & & 0.328 & 0.865 \\
\hline
\end{tabular}

In order to make the results of this experiment objective truth, before the experiment, we test and control groups 100 and 200 meters were tested and the results were related to comparative analysis. As shown in Table 3-1, are small gaps in the experimental group before the experiment, the students in the control group of 100 meters and 200 meters, test scores, where the two sets of academic test scores of 100 meters or less the gap was only 0.09 s, then $100 \mathrm{M}$ for two independent samples $\mathrm{T}$ test results showed that $\mathrm{P}$ value $=0.254>0.05$, indicating no significant difference in the experimental group before the experiment, the control group 100M student achievement; empathy experiment before the experiment group and the control group student test scores are a smaller difference 
between 200M and P values less than 0.05, the experiment also shows that among the control group, students in the experimental group 200M was not a significant difference. In summary, the experimental control group before the experimental group sprint achievement significant difference, no, this discharge this experiment Students' differences, thus contributing to results of scientific authenticity.

\subsection{Comparative analysis of the control group before and after the experiment}

Table 3-2 Related statistics Quality Index test and T-test control group before and after the experiment

\begin{tabular}{cccc}
\hline & number of people & 100 meters & 200meters \\
\hline Before the & 160 & $14.65 \mathrm{~s}$ & $26.12 \mathrm{~s}$ \\
experiment & 160 & $14.27 \mathrm{~s}$ & $25.26 \mathrm{~s}$ \\
After the experiment & & 0.0368 & 0.0487 \\
$\mathrm{P}$ & & \\
\hline
\end{tabular}

Track and field sports as the basis of projects, has been called the mother of sports; its technical mastery of the radiation of other sports to some extent. The Chinese University attaches great importance to track and field has always been to carry out projects in the school physical education teaching, but teaching methods, means still walking, running mainly in the form of relatively simple, boring, students learn initiative and enthusiasm has shown a weakening trend. This article is to break the traditional teaching methods, the use of heuristic teaching to enhance students' learning initiative. By four months of traditional teaching, the students found the $100 \mathrm{M}, 200 \mathrm{M}$ scores were higher (P $<0.05$ ), indicating that traditional teaching methods can improve student achievement sprint.

\subsection{Comparison of experimental and control groups after the experiment teaching}

Table 3-3 Related statistics Quality Index test and T-test before and after the experiment experiments

\begin{tabular}{cccc}
\hline & number of people & 100 meters & 200 meters \\
\hline Before the experiment & 160 & $14.56 \mathrm{~s}$ & $25.36 \mathrm{~s}$ \\
After the experiment & 160 & $13.15 \mathrm{~s}$ & $23.56 \mathrm{~s}$ \\
$\mathrm{P}$ & & 0.00213 & 0.00324 \\
\hline
\end{tabular}

Shown by Table 3-3, the same four months after the sprint technique teaching by heuristic method of teaching found that the experimental group of students from the $100 \mathrm{M}$ scores before the experiment after experiment $14.56 \mathrm{~s}$ to $13.15 \mathrm{~s}$, both to improve the $1.41 \mathrm{~s}$, mathematical statistics through SPSS $\mathrm{P}<0.05$, illustrates the heuristic teaching method for $100 \mathrm{M}$ more significant performance impact; 200M project results from the experiment before the experiment after 25.36s to 23.56s, both to improve the 1.80s ( $\mathrm{P}<0.05$ ), the same way through SPSS mathematical statistics $\mathrm{P}<$ 0.05 , also illustrates the heuristic teaching method for $200 \mathrm{M}$ more significant performance impact. In summary, this new heuristic teaching method teaching methods to improve teaching effectiveness sprint projects and students' scores have a significant role.

\subsection{Comparison of experimental and control groups after the experiment teaching}

Table3- 4 Statistical indicators related to quality testing and T-test experimental and control groups after the experiment 


\begin{tabular}{cccc}
\hline & number of people & 100 meters & 200 meters \\
\hline experimental group & 160 & $13.15 \mathrm{~s}$ & $23.56 \mathrm{~s}$ \\
control group & 160 & $14.27 \mathrm{~s}$ & $25.26 \mathrm{~s}$ \\
$\mathrm{P}$ & & 0.03587 & 0.05263 \\
\hline
\end{tabular}

Table 3-4 in mathematical statistics showed, $\mathrm{P}=0.03587<0.05$, showed that the experimental group had a significant role in improving the performance of the experiment $100 \mathrm{M}$; empathy $\mathrm{P}=$ $0.05263<0.05$, also surface in the control group in the experiment $200 \mathrm{M}$ scores also raise significant role. In summary, the experimental group and control group before the experiment a comparative analysis found that the two groups before the experiment results are not significant differences between the students and the $100 \mathrm{M}, 200 \mathrm{M}$ average achievement gap is small, then the four months through traditional teaching, heuristic teaching, the experimental group, 100M, 200M average score in the control group were improved greatly in the experimental group $100 \mathrm{M}, 200 \mathrm{M}$ grade point average increase rate was higher than the control group. Finally, mathematical statistics found between the experimental and control groups It showed no significant differences, which visually illustrates the heuristic teaching in vocational colleges sprint for teaching, training has a major role.

\section{CONCLUSIONS AND RECOMMENDATIONS}

\section{1 conclusion}

In the experiment the control group, the experimental group, two groups of students tested 100M, $200 \mathrm{M}$ results showed no significant difference, and then the two groups are homogeneous comparable; in the experimental group before and after the $100 \mathrm{M}, 200 \mathrm{M}$ scores were significantly different; experiment 100M before and after the experimental group, 200M scores showed significant differences.

After the experiment the experimental and control groups of students tested 100M, 200M scores were significantly different, indicating an effective heuristic teaching in Higher Vocational Education Course sprint track and field teaching methods can produce better than traditional teaching of teaching effect.

Heuristic teaching can not only stimulate the curiosity of students, but also to enable students to produce a strong track and field learning fun, weakening the single boring Sprint, thus easier to complete the task of teaching PE teachers and improve teaching efficiency.

\section{2 recommendations}

PE teachers should change the traditional track and field sprint teaching philosophy, focusing on changes in teaching methods, teaching methods based on reasonable selection of different classes and students.

PE teachers should pay attention to during the heuristic teaching students the subject, to highlight the initiative of students, but also the need to strengthen the dominant self, but also the self-directed action and initiative of students to achieve seamless and create a good teaching, practice good circulation.

PE teachers should pay attention to the importance of learning heuristic teaching for Sprint, but also need to recognize the strengths and weaknesses of traditional teaching methods, so that traditional teaching methods combined with modern teaching methods, so as to achieve better teaching results.

\section{References}

[1] Wu Zhi Chao, Liu Shao Ceng, Qu Zong Hu. modern teaching theory and Physical Education [M]. Beijing: People Sports Press, 1993: 154-155.

[2] Li Jian ping .University Teaching [M]. Jinan: Shandong University Press, 2008.

[3] Liu Shi Jiao. On the classified PE teaching mode, evaluation and selection from the relationship between teaching and learning [J]. Journal of Physical Education, 1996, (3): 96-97.

[4] Xilintuoya. College Physical Education Teaching Heuristic to improve teaching effectiveness [J]. Inner Mongolia Ancient Technology and Economy, 2002, (7): 132. 